\title{
Fruit sphere microenvironments and berry phenolic content of Cabernet Sauvignon (Vitis vinifera L.) cultivated under rain-shelter systems with coloured plastic film
}

\author{
Jiang-Fei MENG ${ }^{1,2,3 \dagger}$, Tian-Ci SHI ${ }^{1 \dagger}$, Yong $\mathrm{YU}^{1 \dagger}$, Li-Li ZUO ${ }^{1}$, Yu-Shi FU ${ }^{1}$, Qin WANG ${ }^{4}$, Zhen-Wen ZHANG ${ }^{1,2 *}$
}

\begin{abstract}
Rain-shelter cultivation has been proven an important cultivation method for grape-plantings in continental monsoon climate zones, of which white plastic films are the most common shelter material. However, while this method and material reduces the occurrence of the disease, it can also decrease the grape berry quality. Five colours (including red, yellow, blue, purple, and white) of plastic films were covered above Cabernet Sauvignon (Vitis vinifera L.) grapevine rows before veraison. Rain-shelter cultivation reduced air temperature, wind speed, and total solar radiation and enhanced relative humidity in the fruit sphere of grapevines. For each particular colour plastic film, the irradiance of its corresponding spectrum band in the canopy of vines was higher than with other colour plastic films. Meanwhile, the blue plastic film treatment significantly promoted the accumulation of total phenolics, anthocyanins, flavonoids, tannins, and phenolic acids more than the other colours of plastic films. Blue plastic films are more beneficial for berry quality promotion of wine grapes, especially Cabernet Sauvignon, under rain-shelter cultivation in continental monsoon climate zones.
\end{abstract}

Keywords: fruit sphere microclimate; grape quality; light quality; plastic films colour; rain-shelter system.

Practical Application: This study will facilitate the production of quality wine using coloured plastic film.

\section{Introduction}

Wine, especially red wine, contains a large amount of various phenolic compounds. These phenolic compounds play crucial roles in wine colour, taste, bitterness, astringency, and microbiological stability (Gómez Gallego et al., 2012; Granato et al., 2010). The wine phenolic composition will mainly depend on phenolics profile of the original grape berry. Therefore, the wine production starts off as grape cultivation and grape quality is also referred to as wine quality potential. The phenolic composition in grape berry is not only related with grape cultivars, but also is regulated by cultivation and management practice (Treutter, 2010). In most of wine-producing regions in the worldwide, excessive rainfall during grape ripening has affected grape berry quality. It is unfavorable for sugar accumulation, organic acid degradation, phenolic compound formation and fruit coloring. Meanwhile, it also can increase the risk of the breeding and spread of some fungal diseases such as downy mildew, white rot, and anthracnose. These adverse impact seriously limit the production of high-quality wine and development of the grape and wine industry.

In order to overcome the disadvantages caused by local climate conditions, the rain-shelter cultivation technique was introduced to viticulture in China and has been increasing in its spread and popularity ( $\mathrm{Li}, 2001)$. Rain-shelter cultivation can effectively prevent the influence of rain on the crops through building shelters. These facilities commonly consist of holders (bamboo and wood or galvanized steel pipe structures) and a covering membrane (made of polyethylene or another material). By preventing contact between rainwater and grape berries, rain-shelter cultivation effectively decreases the severity of diseases, improves fruit yield, and achieves satisfactory economic and social benefits compared to open-field cultivation (Sun et al., 2006; Wang et al., 2011; Meng et al., 2012). White plastic films are the most common shelter material. Unfortunately, grape fruits grown under covers present higher contents of titratable acidity and a lower content of total anthocyanins than those picked from plants grown without the plastic covering (Detoni et al., 2007; Meng et al., 2012). Meanwhile, grape fruit maturity was postponed and extended due to changes in the microclimate of fruits spheres (Chavarria et al., 2009; Meng et al., 2012). It has been confirmed that the impermeable plastic coverings above the grapevine rows increased the air temperature and decreased the photosynthetic radiation and wind speed. The coverings interfered with the quality of the incoming solar radiation, mainly by reducing the irradiance of the ultraviolet band and also by reducing the ratio between the irradiance of red and far-red bands (Cardoso et al., 2008; Chavarria et al., 2009).

Light plays vital roles in plant growth, which is not only involved in activating photosynthesis and the energy source for vine growth, but also in regulating photomorphogenesis,

\footnotetext{
Received 25 Sept., 2016

Accepted 24 May, 2017

${ }^{1}$ College of Enology, Northwest A\&F University, Yangling, Shaanxi, China

${ }^{2}$ Shaanxi Engineering Research Center for Viti-Viniculture, Yangling, Shaanxi, China

${ }^{3}$ Heyang Experimental and Demonstrational Stations for Grape, Northwest A\&F University, Heyang, Shaanxi, China

${ }^{4}$ Institute of Economic Forest, Xinjiang Academy of Forestry Sciences, Urumqi, Xinjiang, China

*Corresponding author: zhangzhw60@nwafu.edu.cn

${ }^{\dagger}$ These authors contributed equally to this work.
} 
photoperiodic response, and plant endogenous biological rhythms (Chory \& Wu, 2001; Pierik et al., 2009). In the visible region, the photosynthetically active portions (blue and red) are efficiently absorbed. In contrast, radiation in the green spectrum is either reflected or transmitted, giving leaves their green colour (Jackson, 2008). Therefore, light quality (e.g., the specific wavelength of light) is important for grape development and ripening. Some research has indicated that red and blue LEDs (light emitting diodes) induced sugar, anthocyanin, and stilbene accumulation, and affect abscisic acid metabolism (Kondo et al., 2014; Ahn et al., 2015). Therefore, influencing light quality by selective plastic films may serve as a non-chemical growth- regulating tool for plant production in greenhouses (Patil et al., 2001; Casierra-Posada et al., 2012). However, to our knowledge, there are few published studies on the effect of coloured plastic films cover on fruit sphere microenvironments and berry composition of wine grape cultivated under rain-shelter system.

Based on this lack of knowledge, the objective of this study was to screen for the kinds of shelter plastic films by evaluating fruit sphere microclimate and berry composition of wine grapes cultivated under rain-shelter system. From a practical standpoint, this study was carried out to provide sufficient experimental evidence for the improvement of berry quality of wine grapes cultivated under rain-shelter system using different colours of plastic films.

\section{Materials and methods}

\subsection{Planting material and trial design}

The two-year study (2013 and 2014) was conducted at the Grape Demonstration Base of the Jingyang Heyue-Fengrun agriculture Co., Ltd., Jingyang County, Shaanxi Province, China $\left(34^{\circ} 39^{\prime} 15^{\prime \prime} \mathrm{N}, 108^{\circ} 44^{\prime} 35^{\prime \prime} \mathrm{E}\right)$, which is in a temperate continental monsoon climate zone with annual sunshine of $2195.2 \mathrm{~h}$, an average annual temperature of $13{ }^{\circ} \mathrm{C}$, annual precipitation of $548.7 \mathrm{~mm}$, and an average annual frost-free period of $213 \mathrm{~d}$. Rows of own-rooted Cabernet Sauvignon (Vitis vinifera L.) vines (planted in 2009) were oriented north-south on flat terroir with sandy soil. Vines were arranged in a between-row and within-row spacing of $2.5 \times 0.8 \mathrm{~m}$, respectively, and pruned to two buds per spur. Vines were trained to a bilateral cordon at $0.6 \mathrm{~m}$ above ground, in which shoots were trained upwards and each vine carried approximately 20 grape clusters. The vertical shoot-positioned canopies were uniformly managed.

Eighteen rows of vines (60 vines for each row) were divided into six groups with 3 rows (replicates) in each group. Group one was a control and cultured on an open field (open-field cultivation). Group two to six were cultured under a rain-shelter cultivation system covered with red (R), yellow $(\mathrm{Y})$, blue (B), purple $(\mathrm{P})$, and white $(\mathrm{W})$ plastic films, respectively. Shelters were built along with vines rows before berry colouration (late in July) and were 2.2 meter high, 1.7 meter wide, and were covered with transparent and different colour polyethylene film (0.06 $\mathrm{mm}$ thickness). The sugar content and titratable acids in the grape berries were recorded during ripening. Clusters were harvested at their physiological maturity from the vineyards according to local winery requirements and weather conditions
(16/09/2013 and 19/09/2014). Three hundred berries of each treatment were randomly selected from the collected clusters. These samples were stored at $-80^{\circ} \mathrm{C}$ for subsequent analysis for their physicochemical composition.

\subsection{Measurement of fruit sphere microenvironments}

A multiparameter moisture monitor (FM-DZY, Hebei Feimeng Electronic Technology Co., Ltd., Handan, Hebei, China) was used to record air temperature, air humidity, and wind speeds of the fruit spheres in 2014. The probes for air temperature, air humidity, and wind speed were fastened around grape clusters at 0.7 to $0.9 \mathrm{~m}$ from the ground and began to record at the interval of once an hour from plastic films covering to harvest.

A micro-spectrometer (FX2000, Shanghai Ideaoptics Corporation, Shanghai, China) was used to monitor light intensity and spectral distribution under polyethylene film and above vines canopy (approximately $1.9 \mathrm{~m}$ from the ground) in 2014 . The detecting time was chosen as 11:00-13:00 (Chinese Standard Time) at the interval of every $10 \mathrm{~d}$ from plastic films covering to harvest. The results represent averaged value from 4 measuring points.

\subsection{Analysis of total phenolics and total anthocyanins}

A $0.75 \mathrm{~g}$ sample of grape skin dry powder was extracted with ultrasonic assistance in $15 \mathrm{~mL}$ of acidified methanol solution (1 M HCl in $80 \%$ methanol) in an external water bath at $25^{\circ} \mathrm{C}$ for $30 \mathrm{~min}$. After extraction, the extracts were centrifuged at $8000 \times \mathrm{g}$ for $10 \mathrm{~min}$ at $4{ }^{\circ} \mathrm{C}$. The extraction procedure was repeated four times under identical conditions; then, the four supernatants were combined and stored at $-20^{\circ} \mathrm{C}$ in the dark until use.

The total phenolic content (TPC) was estimated using the Folin-Ciocalteu method (Singleton \& Rossi, 1965) and the results are expressed as milligrams of gallic acid equivalents (GAE) per gram of dry berry skins (mg GAE/g DW). The total anthocyanin content (TAC) was estimated using the $\mathrm{pH}$ differential method (Wrolstad, 1976) and the results are expressed as milligrams of malvidin-3-glucoside equivalents (MGE) per gram of dry berry skins (mg MGE/g DW). The tannin content (TANC) was determined by methyl cellulose precipitation (Sarneckis et al., 2006) and the results are expressed as milligrams of (+)-catechin equivalence (CE) per gram of dry berry skin (mg CE/g DW).

\subsection{Analysis of some individual phenolic compounds}

Preparation and analysis of non-anthocyanin phenolic compounds in the grape berries was performed using a previously identified method (Cheng, 2008). For non-anthocyanin phenolic compounds in grape skins, triplicate samples of the pulverized berry skins of each treatment ( $2.00 \mathrm{~g}$ dry weight) were exhaustively extracted four times with $5 \mathrm{~mL}$ of distilled water and $45 \mathrm{~mL}$ of ethyl acetate in an orbital shaker (SHZ-88A, Taicang Experiment Equipment Factory, Jiangsu, China) for $30 \mathrm{~min}$ at $20^{\circ} \mathrm{C}$ to avoid thermal degradation. Then, these organic phases were combined and evaporated until dry in a rotary evaporator (SENCO-R series; Shanghai Shensheng Biotech Co. Ltd., Shanghai, China) at $35^{\circ} \mathrm{C}$ under vacuum. Subsequently, the dried residuals were re-dissolved 
in $5 \mathrm{~mL}$ of methanol (HPLC grade). The methanol solution was filtered through a $0.45-\mu \mathrm{m}$ organic membrane and analysed by high performance liquid chromatography (HPLC) coupled with a diode array detector (DAD) (LC-2010A, Shimadzu, Japan).

The compounds were eluted using a Hibar RT Lichrospher SB-C18 column $(250 \mathrm{~mm} \times 4.0 \mathrm{~mm}, 5 \mu \mathrm{m})$ and detected at $280 \mathrm{~nm}$. The column temperature was set to $30^{\circ} \mathrm{C}$. The mobile phases consisted of two phases, A (water-acetic acid, 98:2 v/v) and $\mathrm{B}$ (acetonitrile). The gradient elution conditions were as follows: $0-20 \mathrm{~min}, 0 \%-5 \% \mathrm{~B} ; 20-35 \mathrm{~min}, 5 \%-15 \% \mathrm{~B}$; 35-50 min, $15 \%-30 \%$ B; 50-65 min, 30\% B; 65-75 min, 30\%-0\% B. The flow rate was $1.0 \mathrm{~mL} / \mathrm{min}$, and the injection volume was $10 \mu \mathrm{L}$. Phenolic compounds were identified by comparing their retention times with those of pure standards and by spiking the samples with standard solutions. Quantifications were made using the external standard method.

\subsection{Statistical analysis}

Statistical analysis was performed on three replicates of the same sample using SPSS 17.0 for Windows. A one-way analysis of variance (ANOVA) and Duncan's multiple range test were used to determine significant differences among samples with a significance level of 0.05 .

\section{Results and discussion}

The microclimate factors of vineyards under rain-shelter cultivation, such as air temperature and humidity, photosynthetic radiation, wind speed, and soil moisture content were altered compared to those under open-field cultivation (Rana et al., 2004; Cardoso et al., 2008, Chavarria et al., 2009). Figures 1 and 2 show the microenvironment parameters in the fruit sphere of Cabernet Sauvignon grapevines from open-field cultivation and rain-shelter cultivation with the five colours of plastic films measured in the present study. The change of air temperature, relative humidity, and wind speed displayed similar trends in the fruit sphere of grapevines among these treatments. Because of continuous rainfall, the air temperature and relative humidity among all six treatments had no significant differences from September 5 to 19,2014 . Before that period, as shown in the figures, the air temperature, wind speed, and total solar radiation in the fruit sphere of grapevines under rain-shelter cultivation with the five colours of plastic films were all significantly lower than for the vines uncovered with plastic films (open-field cultivation), while they showed higher relative humidity in the fruit sphere of grapevines under rain-shelter cultivation than open-field cultivation. This result is a little different from those of previous studies, which found that the plastic films coverings above the grapevine rows increased the air temperature, although it also decreased the photosynthetic radiation and wind speed (Cardoso et al., 2008; Chavarria et al., 2009). The low air temperature in the fruit sphere of grapevines under rain-shelter cultivation could be due to decreased total solar radiation compared to open-field cultivation, while high relative humidity may be related to smaller wind speeds under rain-shelter cultivation, since plastic films coverings above the grapevines rows prevent air movement and exchange mainly by reducing the wind speed in the fruit sphere of grapevines.
For the five groups of rain-shelter cultivation with coloured plastic films, the relative humidity and air temperature showed a negative relationship, which suggests that a group with a high air temperature in its fruit sphere will have low relative humidity. This may be because the high air temperature promotes water vapour evapotranspiration and loss in the air around the fruit sphere. Regarding to spectrum components, compared to open-field cultivation, the coverings with different colours of plastic films interfered with the quality of the incoming solar radiation and reduced the irradiance in each spectrum band to various extents. Despite this, the studies of Cardoso et al. (2008)
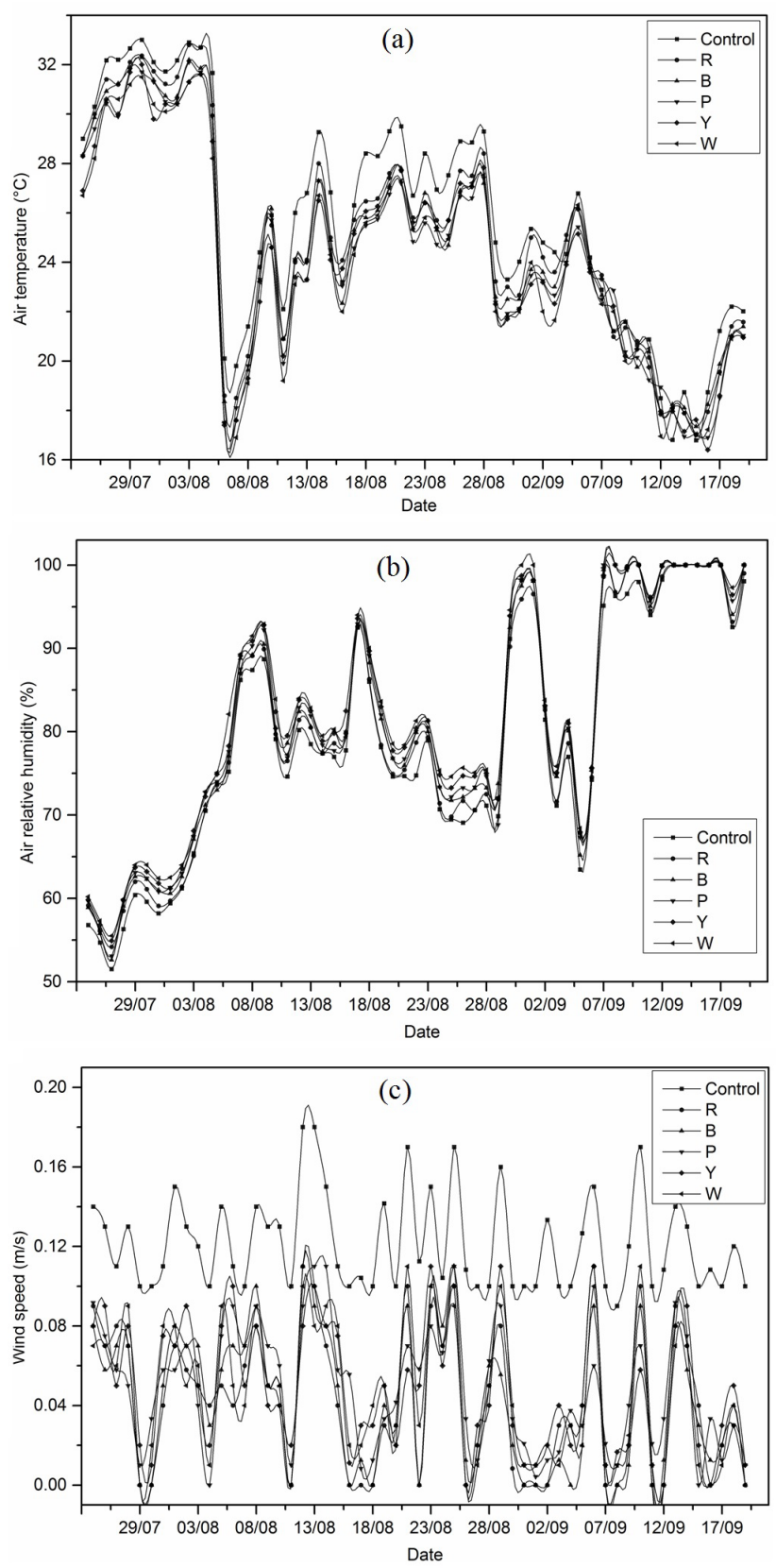

Figure 1. (a) Air temperature; (b) relative humidity and (c) wind speed in the fruit sphere of Cabernet Sauvignon vines cultivated under rain-shelter system with coloured plastic films. 


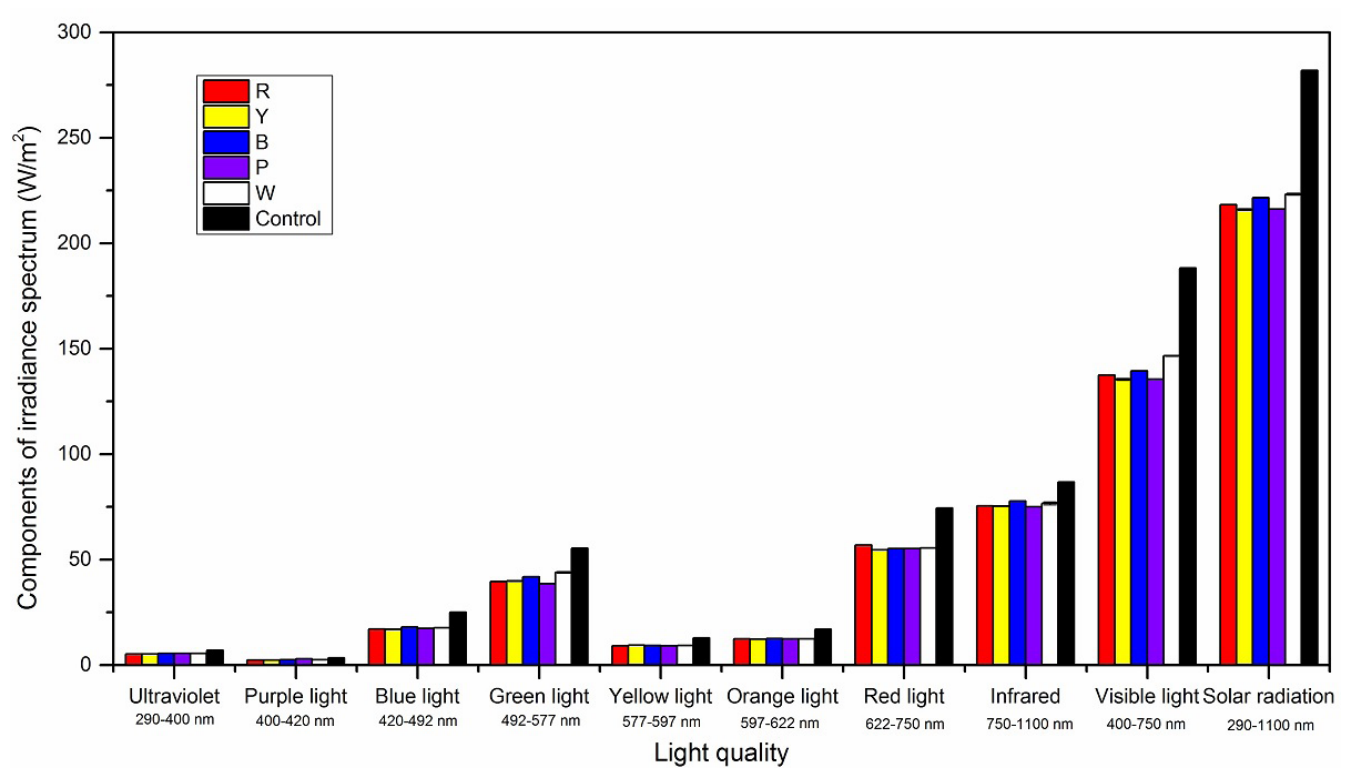

Figure 2. Spectrum distribution in canopies of Cabernet Sauvignon vines cultivated under rain-shelter systems with coloured plastic films.

and Chavarria et al. (2009) suggest that this interference mainly was by reducing the irradiance of the ultraviolet band and the ratio between the irradiance of the red and far-red bands. Interestingly, in our study, for each particular colour plastic film, the irradiance of its corresponding spectrum band was higher than other colour plastic films in the fruit sphere of vines - that is there is a higher irradiance in the red light band for red plastic film, the yellow light band for yellow plastic film, the blue light band for blue plastic film, the purple light and ultraviolet band for purple plastic film, and the visible light band for white plastic film compared to other plastic films. Meanwhile, the irradiance of the green light band through white plastic film, orange light band through red plastic film, and infrared ray band through blue plastic film were higher than with the other plastic films.

Plants use sunlight not only as an energy source for photosynthesis but also as an informational cue to control a broad range of developmental and physiological responses, including seed germination, de-etiolation, directional growth, organelle movement, flowering, and senescence throughout their life cycle (Franklin et al., 2005; Kami et al., 2010). Plants have evolved unique photoreceptor systems to mediate their light responses to broad wavelengths from ultraviolet-B (UV-B) to far-red light (Kong \& Okajima, 2016). Plenty of earlier studies have shown that light quality could have important effects on plant economic quality (Sasakawa \& Yamamoto, 1979; Vijayaraghavan et al., 1979). Therefore, the variation of spectrum components received by plant leaves and in canopies could cause different photoreceptor responses and physiological changes. A previous study showed that a light spectral distribution change could improve the activities of acid invertase, sucrose synthase, and sucrose-metabolizing enzymes and increase the allocation of photosynthetic products to grape berries (Liu et al., 2008). Our results further corroborate this finding. As shown in Table 1, total sugar and titratable acid contents were changed by the colour of the plastic covering above the grapevines rows, and the blue plastic covering significantly increased sugar content in grape berries, which may be related to a higher irradiance in the blue light band.

As a result of the change in grapevine fruit sphere microenvironments by coloured plastic films, not only was the primary metabolism of the grapevines modified, but their secondary metabolism was likely also changed. Polyphenolics are one class of important secondary metabolites, and are also one of the most important quality parameters of wines due to their direct influence on some important organoleptic characteristics of wines, such as colour, flavour, bitterness, and astringency (Garrido \& Borges, 2011). They are also considered major contributors to the antioxidant activity of vegetables and fruits. For these reasons, we examined several important polyphenolic parameters, TPC, TAC, and TANC of grape berries from open-field cultivation and rain-shelter cultivation with different coloured plastic films; the detailed results are shown in Figure 3.

In vintage 2013, the TPC, TAC, and TANC of grape berries were elevated significantly by blue plastic films covering the grapevine rows compared to white plastic film, which is the most common plastic film used in grape rain-shelter cultivation. In vintage 2014, for which excess rainfall during grape ripening in 2014 caused poor maturity and berry quality, the TPC, TAC, and TANC in grape berries for all treatments were significantly lower than vintage 2013. However, the TPC, TAC, and TANC in grape berries of all red, yellow, blue, and purple plastic film treatments were higher than with the white plastic film, and the effect of the purple plastic film was the most significant, followed by the blue plastic film. Judging from the data of vintages 2013 and 2014, blue plastic film is most effective for increasing TPC, TAC, and TANC in grape berries. Cheng et al. (2015) used transparent red, orange, green, blue, and white control light filter film bags composed of strips of a $0.03 \mathrm{~mm}$-thick polyethylene film to cover Yatomi Rosa (Vitis vinifera) grape clusters and obtained a similar result that showed the levels of anthocyanins were significantly 
Table 1. Physio-chemical parameters of Cabernet Sauvignon berries from vines covered with different colours of plastic films.

\begin{tabular}{|c|c|c|c|c|c|c|}
\hline \multirow{2}{*}{ Treatments } & \multicolumn{3}{|c|}{ Vintage 2013} & \multicolumn{3}{|c|}{ Vintage 2014} \\
\hline & Reducing sugars & Titratable acids & $\mathrm{pH}$ value & Reducing sugars & Titratable acids & $\mathrm{pH}$ value \\
\hline $\mathrm{R}$ & $224 \pm 4^{\mathrm{ab}}$ & $4.25 \pm 0.07^{\mathrm{cd}}$ & $3.50 \pm 0.03^{\mathrm{ab}}$ & $175 \pm 2^{c}$ & $6.72 \pm 0.10^{\mathrm{a}}$ & $3.21 \pm 0.02^{\mathrm{d}}$ \\
\hline $\mathrm{Y}$ & $221 \pm 5^{\mathrm{ab}}$ & $4.38 \pm 0.06^{\mathrm{b}}$ & $3.44 \pm 0.02^{\mathrm{c}}$ & $175 \pm 2^{c}$ & $6.29 \pm 0.19^{b}$ & $3.27 \pm 0.01^{c}$ \\
\hline B & $230 \pm 4^{\mathrm{a}}$ & $4.20 \pm 0.09^{\mathrm{d}}$ & $3.54 \pm 0.02^{\mathrm{a}}$ & $202 \pm 3^{\mathrm{a}}$ & $6.16 \pm 0.10^{\mathrm{b}}$ & $3.28 \pm 0.02^{\mathrm{b}}$ \\
\hline $\mathrm{P}$ & $225 \pm 4^{\mathrm{ab}}$ & $4.31 \pm 0.06^{\mathrm{bc}}$ & $3.47 \pm 0.01^{\mathrm{b}}$ & $184 \pm 2^{b}$ & $5.17 \pm 0.16^{\mathrm{d}}$ & $3.35 \pm 0.03^{\mathrm{a}}$ \\
\hline W & $210 \pm 3^{c}$ & $4.50 \pm 0.05^{\mathrm{a}}$ & $3.39 \pm 0.02^{\mathrm{d}}$ & $183 \pm 4^{\mathrm{b}}$ & $5.06 \pm 0.10^{\mathrm{d}}$ & $3.37 \pm 0.03^{\mathrm{a}}$ \\
\hline Control & $219 \pm 4^{b c}$ & $4.29 \pm 0.05^{c}$ & $3.50 \pm 0.03^{\mathrm{ab}}$ & $172 \pm 1^{\mathrm{d}}$ & $5.46 \pm 0.12^{c}$ & $3.33 \pm 0.04^{\mathrm{bc}}$ \\
\hline
\end{tabular}

Note: R, Y, B, P and W represent red, yellow, blue, purple and white plastic film covering above the grapevines rows, respectively. Different lowercase superscript letters in a column represent statistically significant differences between means at $p<0.05$ obtained by one-way ANOVA. Values are expressed as mean \pm standard deviation ( $\mathrm{n}=3$ ). Residual sugar and titratable acids are expressed in $\mathrm{g} / \mathrm{L}$ glucose and $\mathrm{g} / \mathrm{L}$ tartaric acid, respectively.

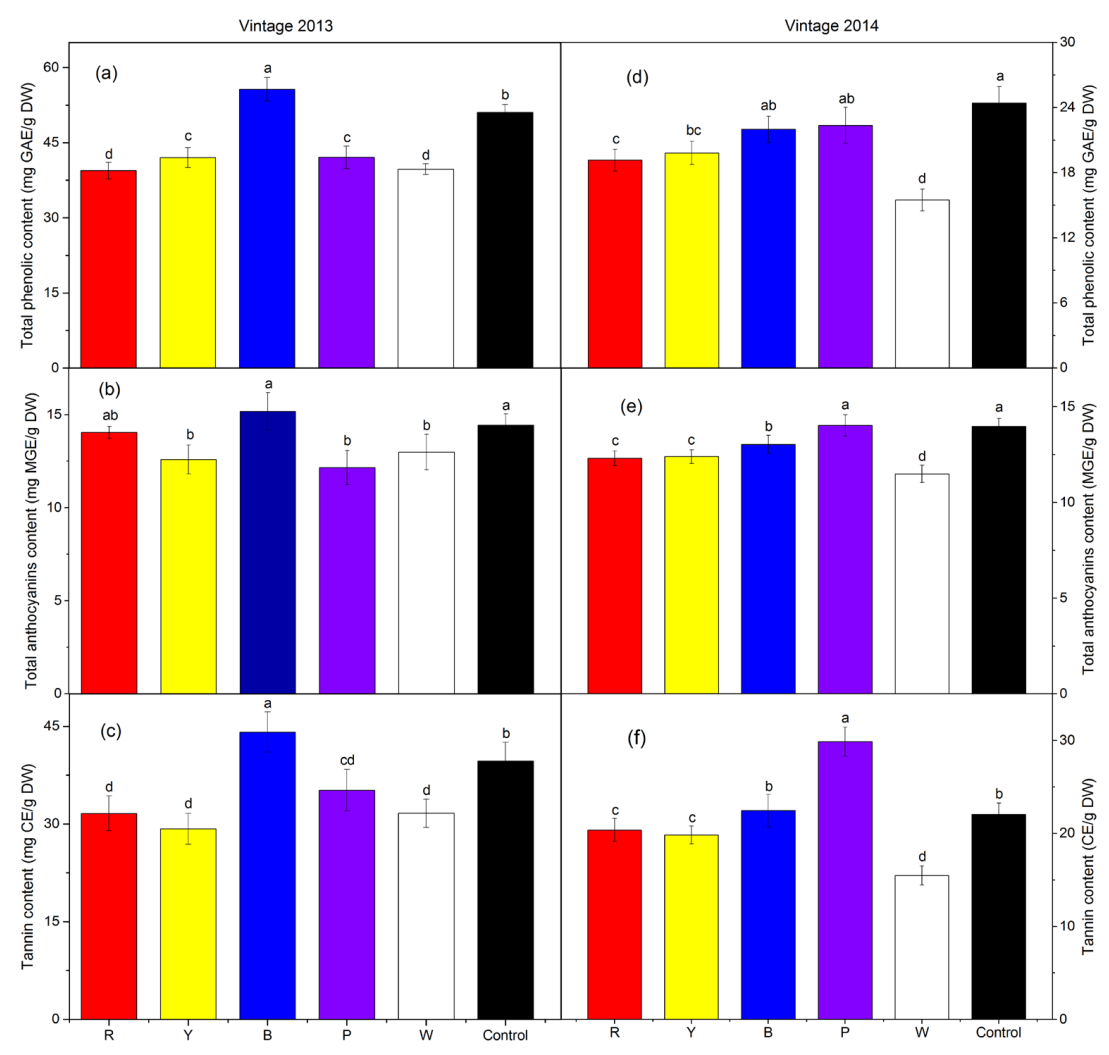

Figure 3. Total phenolic content in (a) 2013 and (d) 2014, total anthocyanin content in (b) 2013 and (e) 2014, and tannin content in (c) 2013 and (f) 2014 of grape berries of Cabernet Sauvignon cultivated under rain-shelter systems with coloured plastic films.

enhanced by blue light filter film and suppressed by red, orange, and green films compared to white film.

This may result from the light quality differences under the various colours of plastic films. Light quality has been reported to affect phenolic metabolism in various plants. Phenolic compounds, especially flavonoids in fruits, were found to be particularly sensitive to light environments, which reflects a possible role of these compounds in photoprotection (Jackson \& Lombard, 1993; Downey et al., 2004). Some research has indicated that red and blue LEDs induce sugar, anthocyanin, and stilbene accumulation, and affect abscisic acid metabolism (Kondo et al., 2014; Ahn et al., 2015). To further understand the effect of coloured plastic film coverings on polyphenolic components in grape berries, we investigated several familiar phenolic compounds in grape berries, including six flavonoids ((+)-catechin, (-)-epicatechin, rutin, quercetin, kaempferol, and morin), seven phenolic acids (gallic acid, caffeic acid, syringic acid, ferulic acid, vanillic acid, ferulic acid, and coumaric acid) and one stilbene (trans-resveratrol). As shown in Tables 2 and 3, in 2013 all six flavonoids analysed from the berries of vines covered with blue and purple plastic films demonstrated higher contents than in those covered by white plastic film, with the increase in blue plastic film more striking. Differing from vintage 2013, in 2014, there was large variation in the contents of the six flavonoids among the five colours of plastic films, with total flavonoid content and three individual flavonoids (rutin, (+)-catechin, and (-)-epicatechin) 
Table 2. Phenolic components of Cabernet Sauvignon berries from vines covered with different coloured plastic films in 2013.

\begin{tabular}{|c|c|c|c|c|c|c|c|c|}
\hline \multirow{2}{*}{ No. } & \multirow{2}{*}{ Phenolic compounds } & \multirow{2}{*}{$\begin{array}{l}\text { Retention time } \\
(\mathrm{min})\end{array}$} & \multicolumn{6}{|c|}{ Phenolic content (mg/Kg DW) } \\
\hline & & & $\mathrm{R}$ & $\mathrm{Y}$ & $\mathrm{B}$ & $\mathrm{P}$ & $\mathrm{W}$ & Control \\
\hline 1 & Rutin & 41.7 & $51.8 \pm 3.7^{\mathrm{c}}$ & $26.0 \pm 2.4^{\mathrm{d}}$ & $85.1 \pm 4.2^{\mathrm{a}}$ & $76.0 \pm 5.3^{b}$ & $71.6 \pm 4.6^{\mathrm{b}}$ & $74.3 \pm 4.4^{\mathrm{b}}$ \\
\hline 2 & $(+)$-Catechin & 19.6 & $62.0 \pm 4.3^{\mathrm{a}}$ & $41.3 \pm 3.3^{\mathrm{b}}$ & $55.8 \pm 5.2^{\mathrm{a}}$ & $35.9 \pm 2.7^{c}$ & $35.1 \pm 3.0^{c}$ & $59.6 \pm 4.0^{\mathrm{a}}$ \\
\hline 4 & Quercetin & 56.2 & $4.3 \pm 0.4^{\mathrm{b}}$ & $3.6 \pm 0.2^{c}$ & $4.9 \pm 0.5 \mathrm{a}^{\mathrm{b}}$ & $5.6 \pm 0.5^{\mathrm{a}}$ & $3.8 \pm 0.3^{c}$ & $5.9 \pm 0.5^{\mathrm{a}}$ \\
\hline 5 & Kaempferol & 63.9 & $1.6 \pm 0.1^{c}$ & $2.1 \pm 0.2^{\mathrm{b}}$ & $4.7 \pm 0.3^{\mathrm{a}}$ & $2.2 \pm 0.2^{\mathrm{b}}$ & $0.2 \pm 0.0^{\mathrm{d}}$ & $2.2 \pm 0.2^{\mathrm{b}}$ \\
\hline 7 & Gallic acid & 5.4 & $1.6 \pm 0.1^{\mathrm{c}}$ & $3.7 \pm 0.3^{\mathrm{a}}$ & $4.1 \pm 0.4^{\mathrm{a}}$ & $3.1 \pm 0.3^{\mathrm{b}}$ & $1.6 \pm 0.2^{c}$ & $2.8 \pm 0.3^{\mathrm{b}}$ \\
\hline 8 & Benzoic acid & 10.0 & $2.3 \pm 0.2^{\mathrm{b}}$ & $1.6 \pm 0.1^{\mathrm{c}}$ & $0.8 \pm 0.1^{\mathrm{d}}$ & $0.7 \pm 0.1^{\mathrm{d}}$ & $8.6 \pm 0.5^{\mathrm{a}}$ & $0.2 \pm 0.0^{\mathrm{e}}$ \\
\hline 9 & Vanillic acid & 23.4 & $4.2 \pm 0.4^{\mathrm{e}}$ & $3.5 \pm 0.5^{\mathrm{e}}$ & $19.5 \pm 1.5^{\mathrm{a}}$ & $14.9 \pm 1.2^{\mathrm{b}}$ & $8.8 \pm 0.5^{\mathrm{d}}$ & $11.3 \pm 1.0^{c}$ \\
\hline 10 & Caffeic acid & 24.2 & $7.4 \pm 0.6^{\mathrm{ab}}$ & $7.0 \pm 0.4^{\mathrm{b}}$ & $7.2 \pm 0.7^{\mathrm{b}}$ & $8.2 \pm 0.7^{\mathrm{a}}$ & $2.9 \pm 0.1^{\mathrm{d}}$ & $6.6 \pm 0.2^{c}$ \\
\hline 11 & Syringic acid & 27.2 & $9.5 \pm 0.7^{c}$ & $15.1 \pm 1.1^{\mathrm{b}}$ & $19.6 \pm 1.4^{\mathrm{a}}$ & $19.6 \pm 1.5^{\mathrm{a}}$ & $7.4 \pm 0.6^{\mathrm{d}}$ & $18.3 \pm 1.4^{\mathrm{a}}$ \\
\hline \multirow{2}{*}{14} & Sum of nonflavonoids & & 56.7 & 43.1 & 76.7 & 75.4 & 47.1 & 68.8 \\
\hline & Sum of phenolics & & 231.8 & 168.9 & 328.4 & 263.2 & 201.0 & 282.0 \\
\hline
\end{tabular}

Note: R, Y, B, P and W represent red, yellow, blue, purple and white plastic film covering above the grapevines rows, respectively. Values are expressed as mean \pm standard deviation (SD). Different letters in each row of total concentrations are significantly different at the 0.05 level according to ANOVA.

Table 3. Phenolic components of Cabernet Sauvignon berries from vines covered with different coloured plastic films in 2014.

\begin{tabular}{|c|c|c|c|c|c|c|c|}
\hline \multirow{2}{*}{ Phenolic compounds } & \multirow{2}{*}{$\begin{array}{l}\text { Retention time } \\
(\mathrm{min})\end{array}$} & \multicolumn{6}{|c|}{ Phenolic Content (mg/kg DW) } \\
\hline & & $\mathrm{R}$ & $\mathrm{Y}$ & $\mathrm{B}$ & $\mathrm{P}$ & $\mathrm{W}$ & Control \\
\hline Rutin & 41.7 & $70.9 \pm 5.3^{\mathrm{a}}$ & $57.3 \pm 3.8^{\mathrm{b}}$ & $57.1 \pm 3.5^{\mathrm{b}}$ & $52.5 \pm 4.2^{\mathrm{bc}}$ & $49.6 \pm 3.5^{c}$ & $61.7 \pm 4.7^{\mathrm{b}}$ \\
\hline$(+)$-Catechin & 19.6 & $19.5 \pm 1.7^{\mathrm{d}}$ & $38.1 \pm 2.7^{\mathrm{a}}$ & $32.3 \pm 2.5^{\mathrm{b}}$ & $23.7 \pm 2.2^{\mathrm{d}}$ & $29.0 \pm 2.6^{c}$ & $33.0 \pm 2.1^{\mathrm{b}}$ \\
\hline Quercetin & 56.2 & $6.1 \pm 0.4^{\mathrm{e}}$ & $9.5 \pm 0.6^{c}$ & $8.1 \pm 0.8^{\mathrm{d}}$ & $10.7 \pm 0.7^{\mathrm{b}}$ & $8.9 \pm 0.7^{c}$ & $13.1 \pm 1.3^{\mathrm{a}}$ \\
\hline Kaempferol & 63.9 & $2.0 \pm 0.1^{\mathrm{d}}$ & $1.0 \pm 0.1^{\mathrm{e}}$ & $5.3 \pm 0.3^{c}$ & $7.8 \pm 0.3^{b}$ & $11.1 \pm 0.8^{\mathrm{a}}$ & $2.7 \pm 0.1^{\mathrm{d}}$ \\
\hline Gallic acid & 5.4 & $0.6 \pm 0.1^{\mathrm{b}}$ & $0.6 \pm 0.0^{\mathrm{b}}$ & $1.6 \pm 0.1^{\mathrm{a}}$ & $0.7 \pm 0.2^{\mathrm{b}}$ & $0.7 \pm 0.1^{\mathrm{b}}$ & $1.4 \pm 0.1^{\mathrm{a}}$ \\
\hline Benzoic acid & 10.0 & $0.6 \pm 0.0^{\mathrm{d}}$ & $0.5 \pm 0.1^{\mathrm{d}}$ & $1.9 \pm 0.2^{\mathrm{a}}$ & $0.1 \pm 0.0^{\mathrm{e}}$ & $0.9 \pm 0.1^{\mathrm{b}}$ & $0.7 \pm 0.0^{c}$ \\
\hline Vanillic acid & 23.4 & $4.1 \pm 0.4^{\mathrm{d}}$ & $6.5 \pm 0.4^{\mathrm{c}}$ & $14.2 \pm 1.4^{\mathrm{ab}}$ & $13.0 \pm 1.0^{\mathrm{b}}$ & $16.1 \pm 1.5^{\mathrm{a}}$ & $11.7 \pm 1.3^{\mathrm{b}}$ \\
\hline Caffeic acid & 24.2 & $3.7 \pm 0.4^{\mathrm{d}}$ & $3.3 \pm 0.4^{\mathrm{d}}$ & $5.8 \pm 0.4^{c}$ & $9.8 \pm 0.6^{\mathrm{a}}$ & $2.2 \pm 0.1^{\mathrm{e}}$ & $6.6 \pm 0.4^{\mathrm{b}}$ \\
\hline Syringic acid & 27.2 & $8.8 \pm 0.9^{\mathrm{d}}$ & $13.8 \pm 1.1^{\mathrm{c}}$ & $15.3 \pm 1.2^{\mathrm{b}}$ & $18.0 \pm 1.8^{\mathrm{a}}$ & $16.5 \pm 1.6^{\mathrm{ab}}$ & $12.6 \pm 1.2^{c}$ \\
\hline Sum of nonflavonoids & & 30.7 & 45.6 & 66.3 & 57.9 & 60.1 & 73.4 \\
\hline Sum of individual phenolics & & 209.7 & 293.8 & 318.4 & 288.0 & 298.2 & 325.0 \\
\hline
\end{tabular}

Note: R, Y, B, P and W represent red, yellow, blue, purple and white plastic film covering above the grapevines rows, respectively. Values are expressed as mean \pm standard deviation (SD). Different letters in each row of total concentrations are significantly different at the 0.05 level according to ANOVA.

significantly higher in the blue and yellow plastic films than the white plastic film. Similarly, for phenolic acids in 2013, with the exception of benzoic acid, the content of the phenolic acid compounds detected from the berries of vines covered with blue and purple plastic films were higher than white plastic film, and naturally the sum of total phenolic acids also presented a similar trend, with the sum level of phenolic acids in the blue plastic film treatment group having the highest among all five colours of plastic films. In vintage 2014, the sum level of phenolic acids in the blue plastic film was less than open-field cultivation, but remained the highest among the groups under rain-shelter cultivation. However, trans-resveratrol content, in both vintages 2013 and 2014, was lower in rain-shelter cultivation with all the different colours of plastic films than open-field cultivation, which may be connected with there being lower diseases and biological stresses in the rain-shelter cultivation. Previous studies have 


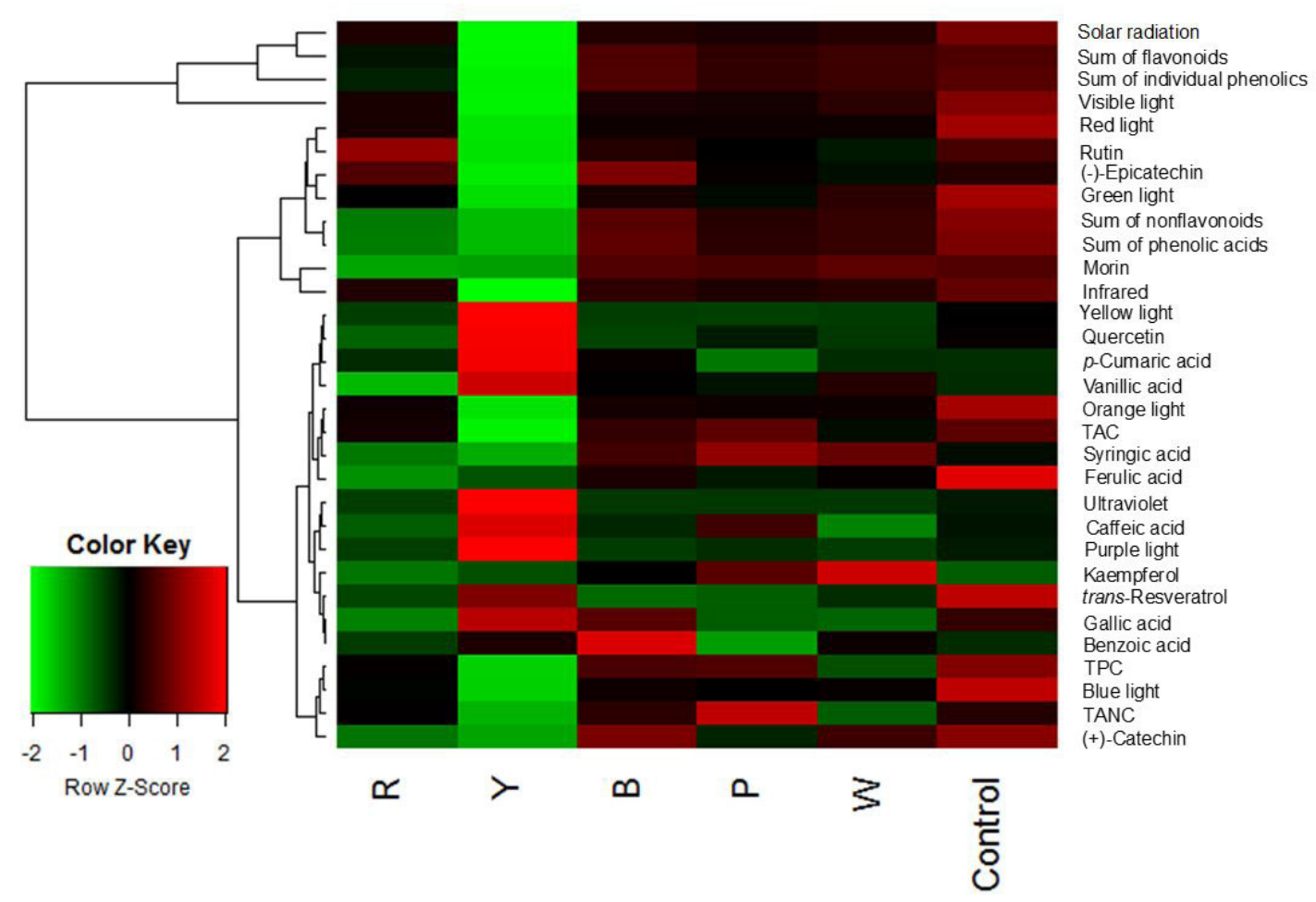

Figure 4. The hierarchically clustered heat map of grape berry phenolic content and grape canopy spectrum irradiance with treatments in rows and phenolic components in columns. Colour bar defines concentration fold change.

confirmed that resveratrol is a major phytoalexin and positively correlated with grapevine disease resistance (Shi et al., 2014).

In order to better understand the relationship between phenolic content and light quality, cluster analysis was performed using grape berry phenolic content and grape canopy spectrum irradiance as variables. As shown in Figure 4, blue light irradiance, TPC, TANC, and (+)-catechin could be clustered within a short hierarchical distance, indicating that they had similar variation tendencies and a high correlation. It was further suggested that the high content of total phenolics, tannins, and $(+)$-catechin could be mainly attributed to the high irradiance of blue light when the blue plastic film covered the grapevine rows.

\section{Conclusions}

In this study, we investigated the effects of different coloured plastic films covering Cabernet Sauvignon grapevine rows before veraison on the fruit sphere microenvironment and phenolic components of mature grape fruits. The rain-shelter cultivation method reduced air temperature, wind speed, and total solar radiation in the fruit sphere of grapevines and enhanced the relative humidity in the fruit sphere of grapevines. For a particular colour plastic film, the irradiance of its corresponding spectrum band in the fruit sphere of vines was higher than with other coloured plastic films. Meanwhile, the blue plastic film treatment significantly promoted the accumulation of total phenolics, anthocyanins, flavonoids, tannins, and phenolic acids compared to the other colours of plastic films.

\section{Acknowledgements}

This study was supported by the Scientific Research Start-up Funds of Northwest A\&F University (2452015309), Chinese Universities Scientific Fund (2452016089) and China Agriculture Research System for Grape Industry (CARS-30-zp-9).

\section{References}

Ahn, S. Y., Kim, S. A., Choi, S. J., \& Yun, H. K. (2015). Comparison of accumulation of stilbene compounds and stilbene related gene expression in two grape berries irradiated with different light sources. Horticulture, Environment and Biotechnology, 56(1), 36-43. http:// dx.doi.org/10.1007/s13580-015-0045-x.

Cardoso, L. S., Bergamaschi, H., Comiran, F., Chavarria, G., Marodin, G. A. B., Dalmago, G. A., Santos, H. P., \& Mandelli, F. (2008). Micrometeorological alterations in vineyards by using plastic covering. Pesquisa Agropecuária Brasileira, 43, 441-444. http:// dx.doi.org/10.1590/S0100-204X2008000400001.

Casierra-Posada, F., Peña-Olmos, J. E., \& Ulrichs, C. (2012). Basic growth analysis in strawberry plants (fragaria sp.) exposed to different radiation environments. Agronomia Colombiana, 1, 25-33.

Chavarria, G., Cardoso, L. S., Bergamaschi, H., Santos, H. P., Mandelli, F., \& Marodin, G. A. B. (2009). Microclimate of vineyards under protected cultivation. Ciência Rural, 39, 2029-2034. http://dx.doi. org/10.1590/S0103-84782009005000147.

Cheng, J. H., Wei, Z., \& Wu, J. (2015). Effect of light quality selective plastic films on anthocyanin biosynthesis in Vitis vinifera L. cv. Yatomi Rosa. Journal of Agricultural Science and Technology, 17, 157-166. 
Cheng, Y. F. (2008). Study on the method of determination of monophenol in grape berry and wine (Master's dissertation). Northwest A\&F University, Shaanxi.

Chory, J., \& Wu, D. (2001). Weaving the complex web of signal transduction. Plant Physiology, 125(1), 77-80. PMid:11154301. http://dx.doi.org/10.1104/pp.125.1.77.

Detoni, A. M., Clemente, E., \& Fornari, C. (2007). Productivity and quality of grape "Cabernet Sauvignon" produced in organic sistem under plastic covering. Revista Brasileira de Fruticultura, 29, 530-534. http://dx.doi.org/10.1590/S0100-29452007000300023.

Downey, M. O., Harvey, J. S., \& Robinson, S. P. (2004). The effect of bunch shading on berry development and flavonoid accumulation in shiraz grapes. Australian Journal of Grape and Wine Research, 10(1), 55-73. http://dx.doi.org/10.1111/j.1755-0238.2004.tb00008.x.

Franklin, K. A., Larner, V. S., \& Whitelam, G. C. (2005). The signal transducing photoreceptors of plants. The International Journal of Developmental Biology, 49(5-6), 653-664. PMid:16096972. http:// dx.doi.org/10.1387/ijdb.051989kf.

Garrido, J., \& Borges, F. (2011). Wine and grape polyphenols-A chemical perspective. Food Research International, 44(10), 3134-3148. http:// dx.doi.org/10.1016/j.foodres.2011.11.001.

Gómez Gallego, M. A., Gómez García-Carpintero, E., Sánchez-Palomo, E., González Viñas, M. A., \& Hermosín-Gutiérrez, I. (2012). Oenological potential, phenolic composition, chromatic characteristics and antioxidant activity of red single-cultivar wines from Castilla-La Mancha. Food Research International, 48(1), 7-15. http://dx.doi. org/10.1016/j.foodres.2012.02.010.

Granato, D., Katayama, F. C. U., \& Castro, I. A. (2010). Assessing the association between phenolic compounds and the antioxidant activity of Brazilian red wines using chemometrics. LebensmittelWissenschaft + Technologie, 43(10), 1542-1549. http://dx.doi. org/10.1016/j.lwt.2010.05.031.

Jackson, D. I., \& Lombard, P. B. (1993). Environmental and management practices affecting grape composition and wine quality: a review. American Journal of Enology and Viticulture, 44, 409-430.

Jackson, R. S. (2008). Wine Science: principles and applications (3rd. ed.). Amsterdam: Elsevier Inc.

Kami, C., Lorrain, S., Hornitschek, P., \& Fankhauser, C. (2010). Lightregulated plant growth and development. Current Topics in Developmental Biology, 91, 29-66. PMid:20705178. http://dx.doi. org/10.1016/S0070-2153(10)91002-8.

Kondo, S., Tomiyama, H., Rodyoung, A., Okawa, K., Ohara, H., Sugaya, S., Terahara, N., \& Hirai, N. (2014). Abscisic acid metabolism and anthocyanin synthesis in grape skin are affected by light emitting diode (LED) irradiation at night. Journal of Plant Physiology, 171(10), 823-829. PMid:24877674. http://dx.doi.org/10.1016/j. jplph.2014.01.001.

Kong, S. G., \& Okajima, K. (2016). Diverse photoreceptors and light responses in plants. Journal of Plant Research, 129(2), 111-114. PMid:26860414. http://dx.doi.org/10.1007/s10265-016-0792-5.

Li, S. H. (2001). Grape production in China: in grape production in the asia-pacific region. In M. K. Papademetriou \& F. J. Dent (Eds.), Regional office for asia and the pacific, food and agriculture organization of the united nations. Bangkok: Regional Office for Asia and the Pacific. Retrieved from: http://www.fao.org/docrep/003/x6897e/ x6897e05.htm\#4.\%20GRAPE\%20PRODUCTION\%20IN\%20CHINA/

Liu, L., Xu, X. F., Wang, Y., Li, T. Z., \& Han, Zh. H. (2008). Effect of different reflecting films on berry quality and sucrose metabolism of grape in greenhouse. Guoshu Xuebao, 25(2), 178-181.
Meng, J. F., Ning, P. F., Xu, T. F., \& Zhamng, Z. W. (2012). Effect of rain-shelter cultivation of Vitis vinifera cv. Cabernet Gernischet on the phenolic profile of berry skins and the incidence of grape diseases. Molecules, 18(1), 381-397. PMid:23271472. http://dx.doi. org/10.3390/molecules18010381.

Patil, G. G., Astrid, G. R., \& Moe, R. (2001). Plant morphology is affected by light quality selective plastic films and alternating day and night temperature. Gartenbauwissenschaft, 2, 53-60.

Pierik, R., Keuskamp, D. H., Sasidharan, R., Djakovic-Petrovic, T., Wit, M., \& Voesenek, L.A.C.J. (2009). Light quality controls shoot elongation through regulation of multiple hormones. Plant Signaling \& Behavior, 8(8), 755-756. PMid:19820335. http://dx.doi. org/10.4161/psb.4.8.9179.

Rana, G., Katerji, N., Introna, M., \& Hammami, A. (2004). Microclimate and plant water relationship of the "overhead" table grape vineyard managed with three different covering techniques. Scientia Horticulturae, 102(1), 105-120. http://dx.doi.org/10.1016/j.scienta.2003.12.008.

Sarneckis, C. J., Dambergs, R. G., Jones, P., Mercurio, M., Herderich, M. J., \& Smith, P. A. (2006). Quantification of condensed tannins by precipitation with methyl cellulose: development and validation of an optimised tool for grape and wine analysis. Australian Journal of Grape and Wine Research, 12(1), 39-49. http://dx.doi. org/10.1111/j.1755-0238.2006.tb00042.x.

Sasakawa, H., \& Yamamoto, Y. (1979). Effects of red, far-red and blue light on enhancement of nitrate reductase activity and on nitrate uptake in etiolated rice seedlings. Plant Physiology, 63, 1098-1101. http://dx.doi.org/ 10.1104/pp.63.6.1098.

Shi, J., He, M. Y., Cao, J. L., Wang, H., Ding, J. H., Jiao, Y. T., Li, R. M., He, J., Wang, D., \& Wang, Y. J. (2014). The comparative analysis of the potential relationship between resveratrol and stilbene synthase gene family in the development stages of grapes (Vitis quinquangularis and Vitis vintfera). Plant Physiology and Biochemistry, 74, 24-32. PMid:24246671. http://dx.doi.org/10.1016/j.plaphy.2013.10.021.

Singleton, V. L., \& Rossi, J. A. (1965). Colorimetry of total phenols with phosphomolybdic phosphotungstic acid reagents. American Journal of Enology and Viticulture, 16, 144-158.

Sun, Q. B., Wang, L., Yu, F. F., Sun, J., \& Lu, L. J. (2006). Research Advances in grape rain-shelter cultivation and its matching technique. Journal of Anhui Agriculture Science, 34, 4560-4561.

Treutter, D. (2010). Managing phenol contents in crop plants by phytochemical farming and breeding-visions and constraints. International Journal of Molecular Sciences, 11(3), 807-857. PMid:20479987. http://dx.doi.org/10.3390/ijms11030807.

Vijayaraghavan, S. J., Sopory, S. K. \& Guha-Mukherjee, S. (1979). Ammonium stimulation of nitrate reductase induction in excised leaves of wheat (Triticum nestivum). Zeitschrift fü Pflanzenphysiologie, 93, 395-402. http://dx.doi.org/ 10.1016/S0044-328X(79)80173-7.

Wang, X. J., Xu, D. X., Wang, X. Q., \& Huang, W. D. (2011). The comparative study of rain-shelter on fruit quality of Cabernet Sauvignon. Chinese Agriculture Science, 27, 114-118.

Wrolstad, R. E. (1976). Color and pigment analyses in fruit products (Station Bulletin, No. 624, 20 p). Corvallis: Oregon State University Agriculture Experimental Station. 